\title{
The strategic development of the NSW Health Plan for Prevention of Falls and Harm from Falls Among Older People: 2011-2015; translating research into policy and practice
}

\author{
Andrew J. Milat ${ }^{\mathrm{A}, \mathrm{E}}$, Claire Monger ${ }^{\mathrm{B}}$, \\ Joanne Smith ${ }^{\mathrm{B}}$, Adrian Bauman ${ }^{\mathrm{C}}$, \\ Sally Redman ${ }^{\mathrm{D}}$ and Brendan Goodger ${ }^{\mathrm{B}}$ \\ ${ }^{\mathrm{A}}$ The Sax Institute (formerly ${ }^{\mathrm{B}}$ ) \\ ${ }^{\mathrm{B}}$ Centre for Health Advancement, NSW Department of Health \\ ${ }^{\mathrm{C}}$ School of Public Health, The University of Sydney \\ ${ }^{\mathrm{D}}$ The Sax Institute \\ ${ }^{\mathrm{E} C o r r e s p o n d i n g ~ a u t h o r . E m a i l: ~ a n d r e w . m i l a t @ s a x i n s t i t u t e . o r g . a u ~}$
}

\begin{abstract}
With our rapidly ageing population there is an urgent imperative to minimise the rate of falls and associated injuries. A key challenge to public health is to better conceptualise and contextualise falls prevention evidence for more effective policy making and practice. This paper describes how NSW Health adopted the Nutbeam and Bauman Stages of Research and Evaluation Model in the strategic development of the NSW Health Plan for Prevention of Falls and Harm from Falls Among Older People: 2011-2015. Research evidence has been comprehensively applied to every stage of the development of the Plan and research and evaluation is a key action area within the new Plan. The Stages of Research and Evaluation Model provides a useful overarching framework for policy makers to contextualise and more effectively apply research evidence throughout the policy making process from problem definition to program monitoring.
\end{abstract}

With the rapid ageing population ${ }^{1}$ there is an urgent imperative to reduce rates of falls and fall-related injuries to reduce harm to older people and the burden on the health and aged-care systems. It is now widely accepted that research evidence can enhance policy and practice by assisting in the identification and definition of priorities, informing decisions on policy development and implementation and by evaluating their impact. ${ }^{2-5}$ Falls prevention is no exception. Recent years have seen growth in research evidence on preventing falls in older people, however the question remains how best to achieve this objective when the transfer of new knowledge from research to practice continues to be less than optimal. ${ }^{6-10}$

A key challenge to public health is to better conceptualise and contextualise evidence for more effective policy making and practice. ${ }^{11,12}$ Nutbeam and Bauman provide an overarching framework, the Stages of Research and Evaluation Model, that can assist policy makers in their efforts to more effectively apply research evidence to the policy making process. ${ }^{12}$ Figure 1 shows the different research and evaluation questions and research methods that are applied stage by stage in the planning, evaluation and dissemination of a comprehensive set of health promotion interventions. The initial stages focus on defining the problem and testing interventions, while later stages are concerned with dissemination and adoption of effective practice, all matters vital to comprehensive policy and program development. This paper describes how the NSW Health Centre for Health Advancement (the Centre) adopted this framework in the strategic development process for the NSW Health Plan for Prevention of Falls and Harm from Falls Among Older People: 2011-2015 (the Plan). ${ }^{13}$

The following is a description of how the Centre addressed each of these stages in the strategic development process.

\section{Problem definition}

The Centre commissioned the NSW Injury Risk Management Research Centre at the University of New South Wales (NSW) to conduct two pieces of work to define the scope of the problem. The first of these was The Incidence and Cost of Falls Injury in New South Wales 2006/07 study ${ }^{14}$ which quantified the burden of injury associated with falls in older persons in NSW. The second was the Evaluation Report: Implementation of the NSW State Falls Management Policy. ${ }^{15}$ It reviewed the epidemiology of 


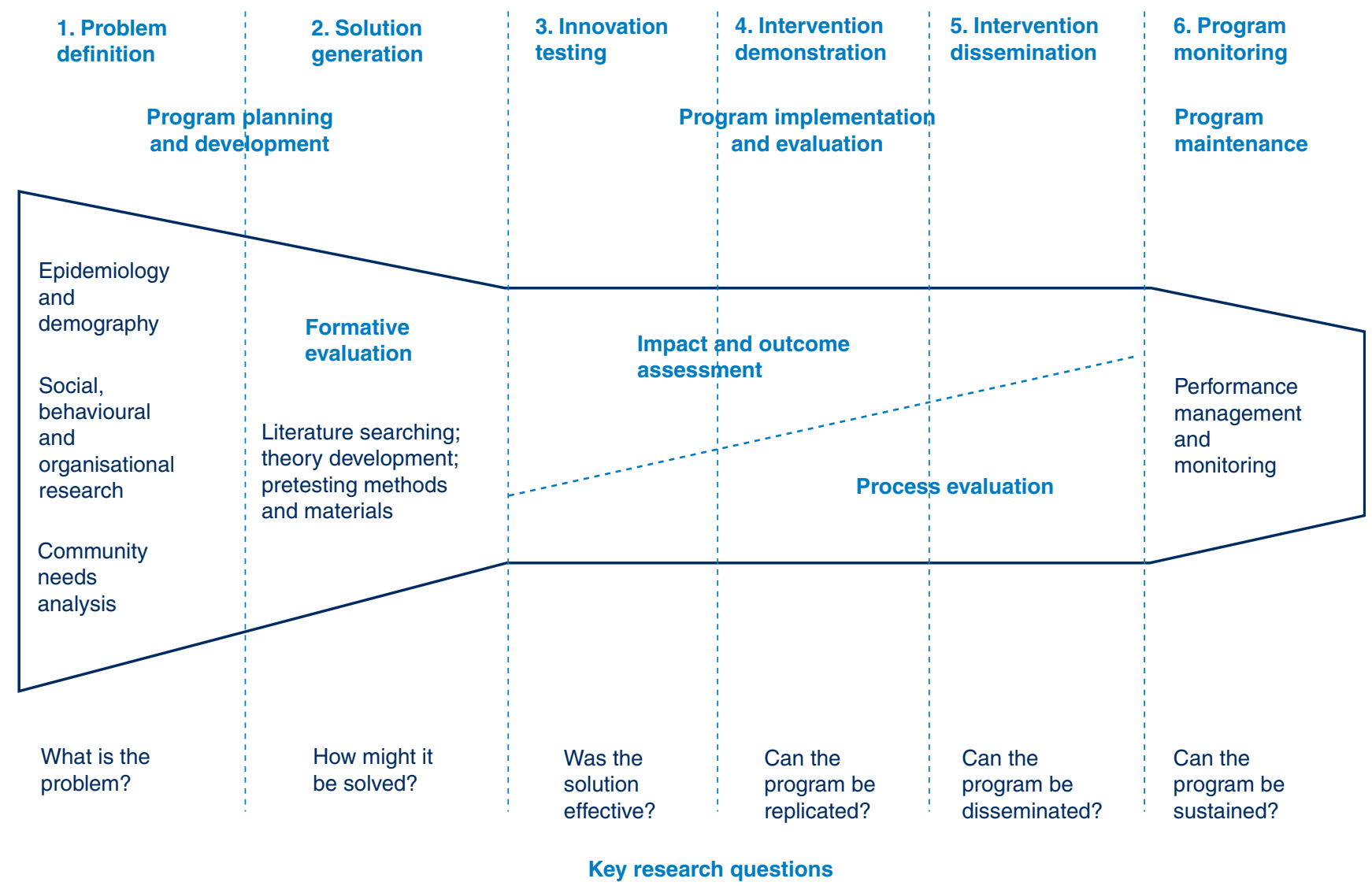

Figure 1. Stages of research and evaluation in public health.

Source: Nutbeam D and Bauman A. Evaluation in a Nutshell - A practical guide to the evaluation of health promotion programs. Sydney: McGraw-Hill; 2006.

falls in NSW and interviewed a range of internal and external stakeholders to ascertain the relative success of the previous policy. Key recommendations of the review were the identification of priority evidence-based interventions, the development of consistent best practice guidelines for implementing key strategies and the development of an evaluation and monitoring framework. ${ }^{15} \mathrm{In}$ response to these recommendations the Centre established a comprehensive research and evaluation investment strategy to fill gaps in evidence to inform the development of the Plan. ${ }^{13}$

\section{Solution generation}

The Centre invested in 'solution generation' by commissioning systematic reviews, best practice recommendations, service reviews, stakeholder and expert consultation, and formative research and pre-testing of social marketing approaches and materials. For example, the Centre identified exercise as a priority intervention due to strong evidence of its role in preventing falls in older people. ${ }^{16}$ In 2008 the Centre commissioned work to inform the development of a falls prevention physical activity strategy for older people which involved interviews with key stakeholders and experts, and a review of Australian and international literature. ${ }^{17}$
Recommendations included: the development of evidencebased minimum standards for community-based falls prevention physical activity programs for older people; the provision of training to exercise providers about these standards; developing a directory of exercise programs that meet the required minimum standards; and commissioning of formative research with older people to better understand what exercise older people are willing to undertake, and the specific enablers and barriers for exercise among this population group.

Following from these recommendations the Centre commissioned Best Practice Recommendations for physical activity to prevent falls in older adults through the Sax Institute's evidence-check commissioning process. ${ }^{18}$ This work was important because despite the large numbers of trials of different forms of exercise for falls prevention ${ }^{19}$ the literature was devoid of specific recommendations on how best to translate this evidence into clear recommendations on the type, frequency and intensity of physical activity programs to prevent falls that could be used by service delivery agencies. Following this piece of work the Centre commissioned a review of the Characteristics of NSW Area Health Service Physical Activity Falls Prevention Programs ${ }^{20}$ to determine what proportion adhered to best practice and to provide recommendations 
on improving the alignment between the evidence and program delivery.

While exercise that improves balance and strength is a key evidence-based intervention for falls prevention, systematic reviews have identified a range of additional interventions that reduce falls among certain sub-sets of older people. ${ }^{18}$ Therefore, in addition to the work focused specifically on exercise, the Centre commissioned the Centre for Health Economic Research and Evaluation, the University of Technology, Sydney, to evaluate the cost-effectiveness of implementation within NSW of each strategy found to be effective in preventing falls amongst people aged 65 years and over living in the community and in residential aged-care facilities. ${ }^{21}$

Social marketing strategies will become an important part of NSW Health action in the area of falls prevention. In support of developing effective communication strategies, the Centre commissioned extensive formative research with older people and carers and health and aged care workers across NSW. ${ }^{22}$ This work provides information about awareness and salience of falls prevention for older people, physical activity participation, general health and wellbeing, and communication needs and preferences. ${ }^{22}$ Formative research is also integral in developing programs and improving existing and ongoing programs. ${ }^{23}$ This type of research assists policy makers to identify and understand the characteristics, interests and needs of target populations that influence their decisions and actions. ${ }^{23}$

With respect to solution generation in clinical settings, the Plan explicitly focuses on implementation of the 2009 evidence-based best practice guidelines from the Australian Commission on Safety and Quality in Health Care, Preventing Falls and Harm From Falls In Older People: Best Practice Guidelines For Australian Hospitals, Residential Aged Care Facilities And Community Care 2009. ${ }^{24}$

\section{Innovation testing and intervention demonstration}

The Centre established the NSW Health Promotion Demonstration Research Grants Scheme in 2000 to fund the former area health services to conduct rigorously designed health promotion intervention research with falls prevention one of three funding priority areas. ${ }^{25}$ This type of research is rarely funded through other existing public health research schemes. ${ }^{25}$ Under the scheme a number of falls prevention randomised controlled trials have been funded to assess the effectiveness of falls prevention interventions focusing on tai chi, ${ }^{26}$ group-based exer$\operatorname{cise}^{27}$ and walking ${ }^{28}$ in community settings, as well as multi-strategic interventions in residential aged-care settings. ${ }^{29}$ Funded research ${ }^{26,27}$ has demonstrated that effective overseas interventions can be replicated in Australian community settings, and by doing so providing local confirmatory evidence on which to base NSW government physical activity recommendations.

The NSW Department of Health also provided funds to support the implementation and evaluation of the Stay on Your Feet project in the former Northern Sydney Central Coast Area Health Service. This community-based initiative seeks to translate and evaluate the application in urban settings of the principles of an earlier North Coast Area Health Service program of the same name which demonstrated success in a rural community. ${ }^{30}$ The Centre has also funded the replication of promising interventions found to be effective internationally such as the evidencebased Otago home-based exercise program in sentinel health areas. ${ }^{31}$

Finally, the Centre has also provided funds to the Clinical Excellence Commission to work with the Ambulance Service of NSW and researchers to better understand fall patterns and develop and test assessment and referral pathways for the management of older people attended to by the Ambulance Service of NSW following a fall but not transported to hospital. ${ }^{32}$

\section{Intervention dissemination}

The Centre has moved to assess whether interventions demonstrated to be effective in randomised controlled trials can be effectively disseminated using different delivery models under 'real world' conditions in the community. Stepping $\mathrm{On}^{33}$ is one such program and is currently undergoing a staged roll out across NSW with a particular emphasis on process evaluation to inform future program implementation models. The program is currently being run in five Local Health Districts with plans to roll it out further in 2012. Once established across NSW the Stepping On program will move from an evaluation frame to a performance management and monitoring phase.

\section{Program monitoring}

A fundamental consideration in the development of the Plan was performance management and monitoring. The Centre commissioned the Injury Risk Management Research Centre to develop an Evaluation and Monitoring Framework for the Plan ${ }^{34}$ in collaboration with an Expert Advisory Committee. The framework comprises process, impact and outcome measures at both the state and local level. The process evaluation focuses on: the resources applied (funds, staff, materials); the activities undertaken (training, services, education, interventions); the processes by which these activities are implemented; and the immediate outputs (staff trained, clients served, assessments conducted) of these activities. The impact evaluation examines the intermediate impacts of the implemented strategies (e.g. risk knowledge and behaviours) and outcome evaluation will assess the overall performance 
against the aims of the Plan (e.g. rate of fall-related hospitalisations and deaths).

The NSW Falls Prevention in Older People Survey series is a central part of the Evaluation and Monitoring Framework, providing process and impact measures over the life of the new Plan. The Falls Survey series includes: a baseline survey conducted with 5681 people aged 65 years and older in $2009,{ }^{35}$ ongoing monitoring modules of a subset of fall-related questions in the continuous NSW Population Health Survey; and a follow-up survey in 2015. To inform question development for the baseline survey a review of options for measuring physical activity beneficial for falls prevention using computer-assisted telephone interviewing surveys was commissioned, resulting in the adoption of new balance-specific activity measures. ${ }^{36}$ These surveys are the most comprehensive suite of measures of their kind in Australia, providing information on fall rates and fall-related injury, physical activity participation, nutritional status, risk and protective factors, mental health, social support and exposure to falls interventions amongst community-dwelling older people. ${ }^{35}$ In addition to the measures already described the Centre's performance-monitoring efforts will be informed by fallrelated data derived from ongoing research infrastructure investments such as the Health Outcomes Information and Statistical Toolkit (Centre for Epidemiology and Research, NSW Department of Health), the 45 and Up Study ${ }^{37}$ and the Centre for Health Record Linkage. ${ }^{38}$

\section{Conclusion}

Research evidence has been comprehensively applied to the development of the NSW Health falls prevention strategy; this focus on research and evaluation continues as a key action area within the Plan. The Stages of Research and Evaluation Model provides a useful overarching framework for policy makers to more effectively apply research evidence throughout the policy making process from problem definition to program monitoring.

\section{Acknowledgments}

We would like to thank colleagues past and present from the NSW Department of Health and NSW Clinical Excellence Commission who have contributed to the strategic development of the NSW Health Plan for Prevention of Falls and Harm from Falls Among Older People: 2011-2015, in particular Liz Develin, Naomi Jackson, Michael Reid and Lorraine Lovitt.

\section{References}

1. Australia Government Treasury. Intergenerational Report 2010. Commonwealth of Australia: Canberra; 2010.

2. Dobrow MJ, Goel V, Upshur RE. Evidence-based health policy: context and utilisation. Soc Sci Med 2004; 58(1): 207-17. doi:10.1016/S0277-9536(03)00166-7
3. Hanney SR, Gonzalez-Block MA, Buxton MJ, Kogan M. The utilisation of health research in policy-making: concepts, examples and methods of assessment. Health Res Policy Syst 2003; 1(1): 2. doi:10.1186/1478-4505-1-2

4. Innvaer S, Vist G, Trommald M, Oxman A. Health policymakers' perceptions of their use of evidence: a systematic review. J Health Serv Res Policy 2002; 7(4): 239-44. doi:10.1258/135581902320432778

5. Mays N, Pope C, Popay J. Systematically reviewing qualitative and quantitative evidence to inform management and policymaking in the health field. $J$ Health Serv Res Policy 2005; 10(Suppl. 1): 6-20. doi:10.1258/1355819054308576

6. Nutbeam D. Improving the fit between research and practice in health promotion: overcoming structural barriers. Can J Public Health 1996; 87(Suppl. 2): S18-23.

7. Brownson RC, Gurney JG, Land GH. Evidence based decision making in public health. $J$ Public Health Manag Pract 1999; 5(5): 86-97.

8. Elliott H, Popay J. How are policy makers using evidence? Models of research utilisation and local NHS policy making. $J$ Epidemiol Community Health 2000; 54(6): 461-8. doi:10.1136/jech.54.6.461

9. Black N. Evidence based policy: proceed with care. BMJ 2001; 323(7307): 275-9. doi:10.1136/bmj.323.7307.275

10. Campbell DM, Redman S, Jorm L, Cooke M, Zwi AB, Rychetnik L. Increasing the use of evidence in health policy: practice and views of policy makers and researchers. Aust New Zealand Health Policy 2009; 6: 21. doi:10.1186/ 1743-8462-6-21

11. Bowen S, Zwi A. Pathways to 'evidence-informed' policy and practice: a framework for action. PLoS Med 2005; 2(7): e166. doi:10.1371/journal.pmed.0020166

12. Nutbeam D, Bauman A. Evaluation in nutshell - A practical guide to the evaluation of health promotion programs. Sydney: McGraw-Hill; 2006.

13. NSW Department of Health. NSW Health Plan for Prevention of Falls and Harm from Falls Among Older People: 2011-2015. North Sydney: NSW Department of Health; 2011.

14. Watson W, Clapperton A. The incidence and cost of falls injury in New South Wales 2006/07 - A Report to NSW Health. Kensington: NSW Injury Risk Management Research Centre; 2010.

15. Watson W. Evaluation Report: Implementation of the NSW State Falls Management Policy. Kensington: NSW Injury Risk Management Research Centre; 2009.

16. Sherrington C, Whitney JC, Lord SR, Herbert RD, Cumming $\mathrm{RG}$, Close JCT. Effective approaches to exercise in the prevention of falls: a systematic review and meta-analysis. $J$ Am Geriatr Soc 2008; 56: 2234-43. doi:10.1111/ j.1532-5415.2008.02014.x

17. The Miller Group. Three Year Physical Activity Action Plan for Older People in NSW. Unpublished report; 2010.

18. Sherrington C, Lord S, Close JCT. Best Practice Recommendations for physical activity to prevent falls in older adults. North Sydney: NSW Department of Health; 2008.

19. Gillespie LD, Robertson MC, Gillespie WJ, Lamb SE, Gates S, Cumming RG et al. Interventions for preventing falls in older 
people living in the community. Cochrane Database Syst Rev 2009; 15(2): CD007146.

20. Sherrington C, Lord S, Close J, Mikolaizak S. Characteristics of NSW Area Health Service Physical Activity Falls Prevention Programs. Sydney: The George Institute for International Health and the Prince of Wales Medical Research Institute; 2009.

21. Church J, Goodall S, Norman R, Haas M. An economic evaluation of community and residential aged care falls prevention strategies in NSW. Sydney: Centre for Health Economic Research and Evaluation; 2010.

22. Consultants TNS. Research Report to inform the development of social marketing activity supporting falls prevention among older people. Unpublished report; 2010.

23. Donovan RJ, Henley N. Social Marketing: Principles and Practices. Sydney: IP Publishing; 2003.

24. Australian Commission on Safety and Quality in Health Care (ACSQHC). Preventing Falls and Harm from Falls In Older People: Best Practice Guidelines For Australian Hospitals, Residential Aged Care Facilities And Community Care. Canberra: Commonwealth of Australia; 2009

25. NSW Department of Health. NSW Health Promotion Demonstration Research Grants Scheme. Available from: http:// www.health.nsw.gov.au/publichealth/healthpromotion/grants/ index.asp (Cited May 2010.)

26. Voukelatos A, Rissel C, Cumming R, Lord S. The Central Sydney Tai Chi Trial: a randomised controlled trial of the effectiveness of tai chi in reducing the risk of falls in older people. Sydney: NSW Department of Health; 2006.

27. Dean C, Rissel C, Sharkey M, Sherrington C, Cumming R, Merom D. Exercise intervention to prevent falls, enhance mobility and increase physical activity in community dwellers after stroke: a randomised controlled trial. Available from: http://www.health.nsw.gov.au/publichealth/healthpromotion/ grants/funding2006.asp\#cim_main-content (Cited July 2010.)

28. Voukelatos A, Merom D, Sherrington C, Watson W, Rissel C. The Walking and Falls Study: a randomised controlled trial investigating the effectiveness of a 12-month self-paced walking program in reducing the risk of falling in older people. Available from: http://www.health.nsw.gov.au/publichealth/ healthpromotion/grants/funding2008.asp\#para_0 (Cited July 2010.)

29. Ward J, Harden M, Gibson R, Byles J. Prevention of falls in Residential Aged Care. North Sydney: NSW Department of Health; 2009.

30. North Coast Public Health Unit. Stay on your feet report. North Sydney: NSW Department of Health; 1992.

31. Robertson MC, Gardner MM, Devlin N, McGee R, Campbell AJ. Effectiveness and economic evaluation of a nurse delivered home exercise programme to prevent falls. 2: Controlled trial in multiple centres. BMJ 2001; 322(7288): 701-4. doi:10.1136/ bmj.322.7288.701

32. Ambulance Service of NSW. Epidemiology of fallers who access health care through triple zero - a research proposal. Ambulance Service of NSW. Unpublished report; 2009.

33. Clemson L, Cumming RG, Kendig H, Swann M, Heard R, Taylor K. The effectiveness of a community-based program for reducing the incidence of falls in the elderly: a randomized trial. $J$ Am Geriatr Soc 2004; 52(9): 1487-94. doi:10.1111/j.15325415.2004.52411.x

34. Watson W. Draft Evaluation framework for NSW Health Plan for the Prevention of Falls and Harm from Falls, 2011-2015. Kensington: IRMRC; Unpublished report; 2011.

35. Centre for Health Advancement and Centre for Epidemiology and Research. New South Wales Falls Prevention Baseline Survey: 2009 Report. North Sydney: NSW Department of Health; 2010.

36. Bauman A, Chau J, Macniven R. Physical activity measurement related to falls prevention. Unpublished report; 2009.

37. The Sax Institute. About the 45 and Up Study. Available from: http://www.45andup.org.au/ (Cited July 2010.)

38. About the Centre for Health Record Linkage. Available from: http://www.cherel.org.au/ (Cited July 2010.) 